\title{
Emplacement of penetrators into planetary surfaces
}

\author{
William W. Anderson, ${ }^{1,4}$ Thomas J. Ahrens, ${ }^{1}$ Andrew Gibson, ${ }^{2}$ Ronald Scott, ${ }^{2}$ and \\ Kojiro Suzuki ${ }^{3}$
}

\begin{abstract}
We present experimental data and a model for the low-velocity (subsonic, 0-1000 $\mathrm{m} / \mathrm{s}$ ) penetration of brittle materials by both solid and hollow (i.e., coring) penetrators. The experiments show that penetration is proportional to momentum/frontal area of the penetrator. Because of the buildup of a cap in front of blunt penetrators, the presence or absence of a streamlined or sharp front end usually has a negligible effect for impact into targets with strength. The model accurately predicts the dependence of penetration depth on the various parameters of the target-penetrator system, as well as the qualitative condition of the target material ingested by a corer. In particular, penetration depth is approximately inversely proportional to the static bearing strength of the target. The bulk density of the target material has only a small effect on penetration, whereas friction can be significant, especially at higher impact velocities, for consolidated materials. This trend is reversed for impacts into unconsolidated materials. The present results suggest that the depth of penetration is a good measure of the strength, but not the density, of a consolidated target. Both experiments and model results show that, if passage through the mouth of a coring penetrator requires initially porous target material to be compressed to $<26 \%$ porosity, the sample collected by the corer will be highly fragmented. If the final porosity remains above $26 \%$, then most materials, except cohesionless materials, such as dry sand, will be collected as a compressed slug of material.
\end{abstract}

\section{Introduction}

Ballistically emplaced penetrators have been proposed as an efficient and inexpensive way to place instruments at the surfaces of a wide range of solar system bodies. This technique can be extended to obtaining samples of surficial materials by the use of hollow penetrators that are subsequently extracted. A good deal of both experimental and theoretical study has been directed toward the problem of projectile penetration into consolidated and unconsolidated geologic materials [Wang, 1971; Young, 1969; Murff and Coyle, 1973; Forrestal et al., 1994; Forrestal and Luk, 1992; Allen et al., 1957]. However, these studies are not sufficiently general to be applicable to both solid and hollow penetrators. We present a new experimental data set for penetration, predominantly by hollow penetrators, but also including solid penetrators. We then present a model for penetration by any type of penetrator by considering hollow penetrators and treating solid penetrators as a special case in which the depth of the hole in the hollow penetrator is zero. The experimental data are used to test the model and to constrain poorly known parameters.

\footnotetext{
'Seismological Laboratory, California Institute of Technology, Pasadena.

${ }^{2}$ Division of Engineering and Applied Science, California Institute of Technology, Pasadena.

${ }^{3}$ Department of Aeronautics and Astronautics, Faculty of Engineering, University of Tokyo, Bunkyo, Tokyo, Japan.

'Department of Geology and Physics, Georgia Southwestern State University, Americus.

Copyright 1996 by the American Geophysical Union.

Paper number 96JE01421.

0148-0227/96/96JE-01421\$09.00
}

\section{Experimental Program}

\section{Experimental Techniques}

During the study, various target materials were impacted by several different types of penetrators. The experiments can be broken down into three basic types. Types 1 and 2 used hollow projectiles that were designed to act as corers, while type 3 experiments used solid penetrators.

Corers for the type 1 experiments were fabricated from either aluminum 2024 alloy ("AL2024") or stainless steel 304 ("SS304") and were open-ended hollow cylinders $1 \mathrm{~m}$ long, with an outer diameter of $44.5 \mathrm{~mm}$ and a wall thickness of $1.25 \mathrm{~mm}$. The cylinder ends were finished to flat surfaces perpendicular to the axis of the cylinder.

During the experiments (Figure 1a), the cylinders were dropped, typically from a height of $13.7 \mathrm{~m}$, into a series of weakly consolidated mixtures of perlite (a highly porous rhyolitic volcanic glass, commercial brand "Redco III") with gypsum plaster and more strongly consolidated mixtures of perlite with Portland cement. The velocity of a cylinder was determined using a system consisting of a laser and photodiode (Mechanical Technologies KD-300-01) which measured the laser radiation reflected from the passing cylinder as a function of time. Dark stripes placed at intervals on the cylinder were detected by this system as a periodic variation in the reflected light intensity (Figure 2). The period of this variation, combined with knowledge of the spacing of the stripes, allowed the velocity to be determined to an accuracy of 0.3-0.5 $\mathrm{m} / \mathrm{s}$ as a function of time before and during penetration of the target.

Separate samples of the target materials for the type 1 experiments were prepared, aged, and stored in the same way as the targets and subjected to a series of static engineering tests 


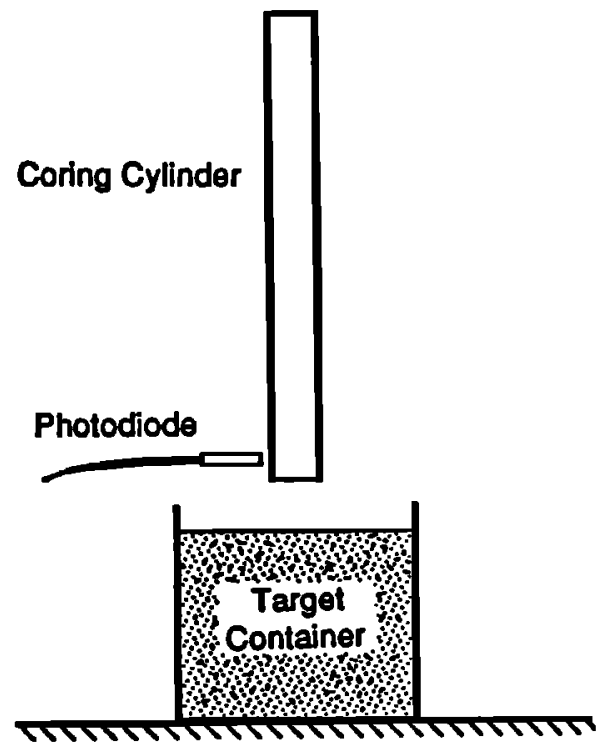

a
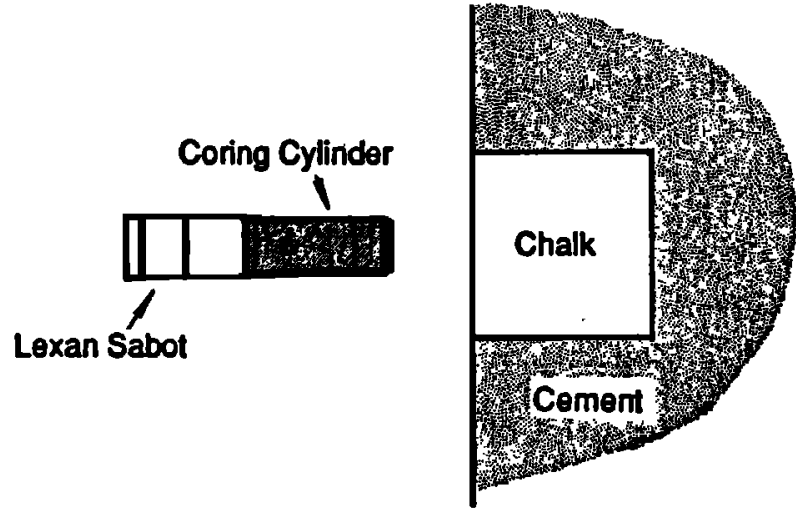

b

Figure 1. Schematic representations of the impact penetration experiments performed in this study. (a) Lowvelocity $(\sim 15 \mathrm{~m} / \mathrm{s})$ impacts with dropped coring tubes. (b) Higher velocity $\left(\sim 10^{2} \mathrm{~m} / \mathrm{s}\right)$ impacts by gunlaunched penetrators.

to determine their properties. In the first type of static test, a standard testing apparatus (MTS Load Frame with internal load cell) was used to measure the unconfined strength of 10.2-cm-long cylindrical samples $5.1 \mathrm{~cm}$ in diameter under uniaxial compression. In the second type of static test, coring tubes like those used in the experiments were pushed into the samples at a rate of $\sim 1 \mathrm{~cm} / \mathrm{min}$, and the force required to maintain that penetration rate was measured as a function of depth of penetration. Figure 3 shows a typical example of the experimental record from one of these experiments. The discontinuities and spikes in the instrumental record are artifacts of the experimental setup, in which the position of the sample had to be readjusted periodically to accommodate the limited travel range of the ram on the MTS Load Frame.

Corers for the type 2 experiments (Figure 4) were openended hollow cylinders fabricated from SS304 or Vascomax C-300 hardened steel ("C300", Rockwell hardness $R_{c}=54$ ), affixed at one end to polycarbonate sabots $20 \mathrm{~mm}$ or $40 \mathrm{~mm}$ in diameter. Each coring cylinder was $50 \mathrm{~mm}$ long, with an outside diameter of $16.9 \mathrm{~mm}$ and a wall thickness of $2.1 \mathrm{~mm}$. Both the inside and outside of the leading edge of the coring cylinder were beveled at an angle of $45^{\circ}$ from the cylinder axis to form a cutting edge. While most of the type 2 penetrators had coring cylinders with constant inner diameters (Figure 4b), those used in two experiments had a lip at the leading edge (Figure 4c), restricting the entrance to an inner diameter of $11.7 \mathrm{~mm}$, while the inner diameter past the lip was 12.7 $\mathrm{mm}$. This allowed the effects of friction and mechanical disruption of the material entering the corer to be studied. In one case, the coring cylinder was actually made of two concentric C300 cylinders separated by a Teflon spacer (Figure 4d). The polycarbonate sabot was designed to remain attached to the coring cylinder during the penetration process. Type 2 penetrator masses ranged from $50 \mathrm{~g}$ to $130 \mathrm{~g}$.
The penetrators were launched by compressed gas or propellant guns at velocities of $35-500 \mathrm{~m} / \mathrm{s}$ into $15 \mathrm{~cm}$ thick blocks of oolitic limestone from Bedford, Indiana, or into 3- to 15-cm thick samples of Dover Chalk, Bishop Tuff, or San Marcos Gabbro, embedded in Portland cement. Impact velocity was measured from the interval between interruption of successive laser beams [Ahrens et al., 1971], and the final depth of penetration was measured after each experiment.

In conjunction with the type 2 experiments, static penetration tests were performed in which the resistance to penctration was measured as a function of depth of penetration. A 10-ton hydraulic press (Enerpac model 65442) was used to apply a load to a coring cylinder, forcing it into the target material. At 5-mm intervals (determined visually from premeasured marks on the coring cylinders), pumping on the ram was

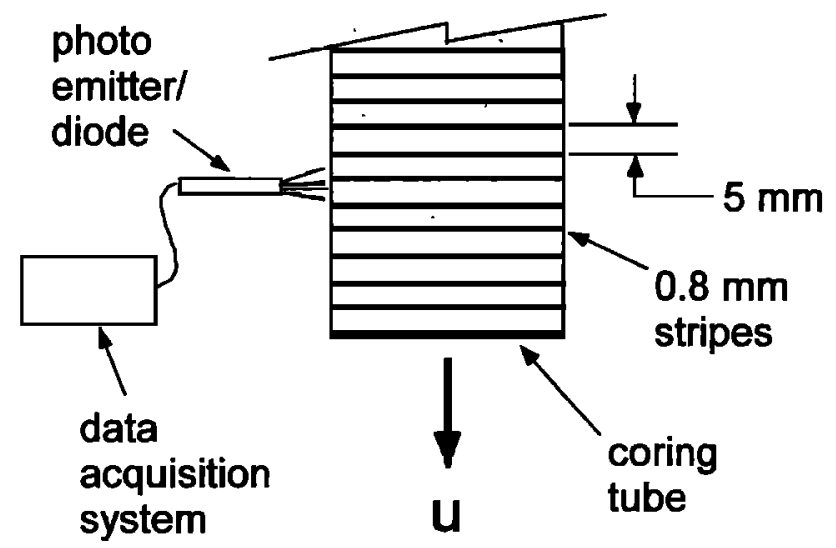

Figure 2. Diagram of velocity measuring system used for type 1 experiments. 


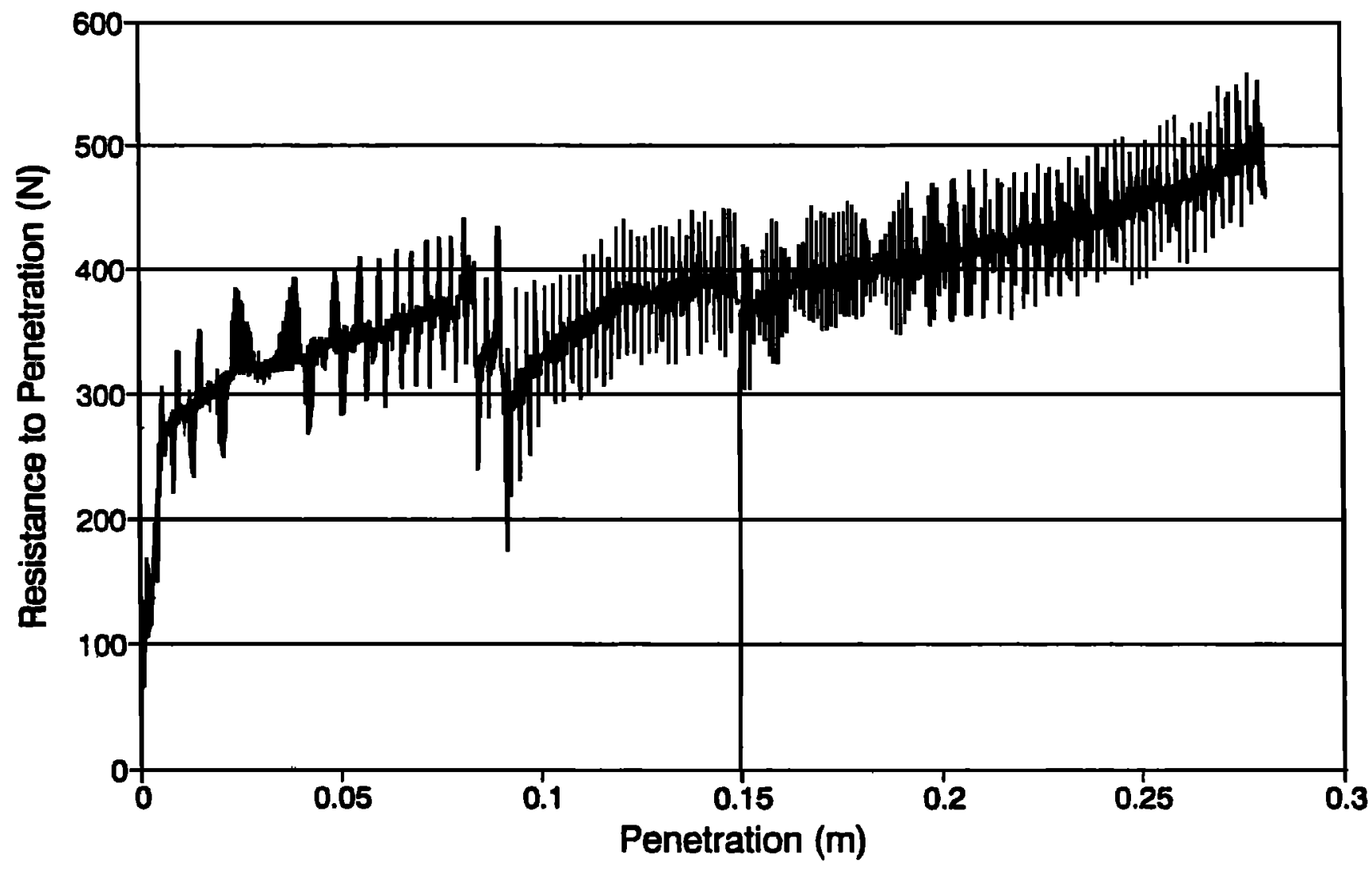

Figure 3. Quasi-static penetration record of type 1 SS304 corer penetrating a perlite-plaster mixture. The frontal cross section of the coring tube is $1.7 \times 10^{-4} \mathrm{~m}^{2}$. The relation of the intercept and slope of the force versus penetration curve (after the initial portion) is given by (1). The spikes in the record are artifacts of the experimental setup.

stopped, and the static force supported by the target at that penetration depth (resulting from friction and the material strength of the target) was determined from the indicated ram oil pressure and the diameter of the ram piston.

Type 3 experiments used solid cylindrical penetrators fabricated from cold-rolled steel ("CRS") or Vascomax C-250 hardened steel ("C250"). The penetrators (Figure 5) were 12.7 $\mathrm{mm}$ in diameter with a total length of $22 \mathrm{~cm}$. The forward end of each penetrator was tapered in a cone with a $15^{\circ}$ half-angle. Two polycarbonate sabots, $\mathbf{4 0} \mathrm{mm}$ in diameter, were attached to each penetrator by engaging screw threads that had been cut into the front-most and rear-most portions of the penetrators. The forward sabot was weakened so that it would break away from the penetrator upon impact with the target.

These penetrators were launched by a compressed-gas gun at velocities in the range $60-110 \mathrm{~m} / \mathrm{s}$. Targets were composed of a perlite-plaster mixture, Dover Chalk, or Bedford limestone, and embedded in Portland cement. The impact velocity was determined in the same way as for type 2 experiments.

\section{Experimental Results}

Table 1 presents directly measured properties of the target and corer materials. The target properties were measured in this study, unless otherwise noted. Missing values in the table represent quantities which were not measured for the relevant material. The static bearing strength $\sigma_{0}$ and dimensionless friction coefficient $\mu_{f}$ against the penetrators are found from the static and quasi-static penetration experiments, where the force, $F_{R}$ resisting penetration is related to the depth of penetration, $x$, by

$$
F_{R}=\sigma_{0}\left(A_{x}+\mu_{f} A_{s}\right)
$$

where $A_{x}$ is the frontal area of the penetrator and $A_{s}$ is the side surface area in contact with the target material (both inside and outside hollow cylinders).

Table 2 and Figure 6 give the experimental results. Because penetration into a half-space requires failure of the target material, we can, as a crude approximation, treat the failed target material as a fluid. Consideration of the forces acting on a body moving through a fluid suggests that the best predictor for depth of penetration into a given material with known mechanical properties is the quantity $m u_{0} / A_{x}$, where $m$ is the mass of the penetrator, $u_{0}$ is the impact velocity, and $A_{x}$ is the projected frontal area of the penetrator (taken in the present case to be the projected frontal area without the sabot). As can be seen from Figure 6, the depth of penetration for each target material is indeed correlated with this quantity. Figure 6 also shows best fit lines constrained to pass through the origin. The inverse slopes of the linear fits have units of density times velocity, i.e., of shock impedance, and support the intuitive expectation that dense or strong materials resist penetration more than weak, low-density materials. The values of the inverse slopes are $3.0 \times 10^{5} \mathrm{~kg} \mathrm{~m}^{-2} \mathrm{~s}^{-1}$ for the perliteplaster mixture, $3.3 \times 10^{5} \mathrm{~kg} \mathrm{~m}^{-2} \mathrm{~s}^{-1}$ for chalk, $3.6 \times 10^{6} \mathrm{~kg} \mathrm{~m}^{-2} \mathrm{~s}^{-1}$ 
for Bishop Tuff, and $2.2 \times 10^{7} \mathrm{~kg} \mathrm{~m}^{-2} \mathrm{~s}^{-1}$ for limestone. It should be noted that in high-velocity experiments involving chalk targets, the projectile also penetrated the cement in which the chalk was mounted, so those experiments are more complicated than simple penetration of a uniform target.

\section{Theoretical Penetration Model}

No previous work has been directed toward models that are generally applicable to both solid and hollow penetrators. Since a solid penetrator can be considered as the special case of a hollow penetrator with a hole of zero depth, we wish to develop the model for a hollow penetrator, which will then be applicable to both situations. The model should predict penetration depth for a given combination of penetrator and target characteristics. Such a model can be used to optimize penetrator designs and analyze penetration data for information about target properties.

\section{Equations of Motion}

Although the physical principles are generally applicable, we restrict our efforts to modeling impacts at sufficiently low velocities that penetrator deformation is negligible $(<1000$ $\mathrm{m} / \mathrm{s}$ ). While the behavior of the penetrator and target as penetration progresses is of primary concern, the transient phenomena occurring at the time of initial contact have important consequences for subsequent behavior. The initial impact generates a shock wave which propagates into both the penetrator and the target. We assume that target failure is a requisite condition for penetration. Thus the shock wave in the target material is a plastic deformation wave. However, since we restrict the model to negligible penetrator deformation, the shock wave in the penetrator is actually a finite amplitude longitudinal elastic wave. The conditions in the shocked target and penetrator materials are governed by the conservation of mass, momentum, and energy and by the requirement that pressure and particle velocity be continuous across the penetrator-target interface. Usually, the velocity $U_{s}$ of a planar shock wave is expressed as a linear function of the particle velocity $u_{p}$ induced by passage of the shock wave, i.e.,

$$
U_{s}=C_{0}+s u_{p}
$$

While the shock wave in the target deviates severely from planarity as it propagates from the projectile-target interface, it is
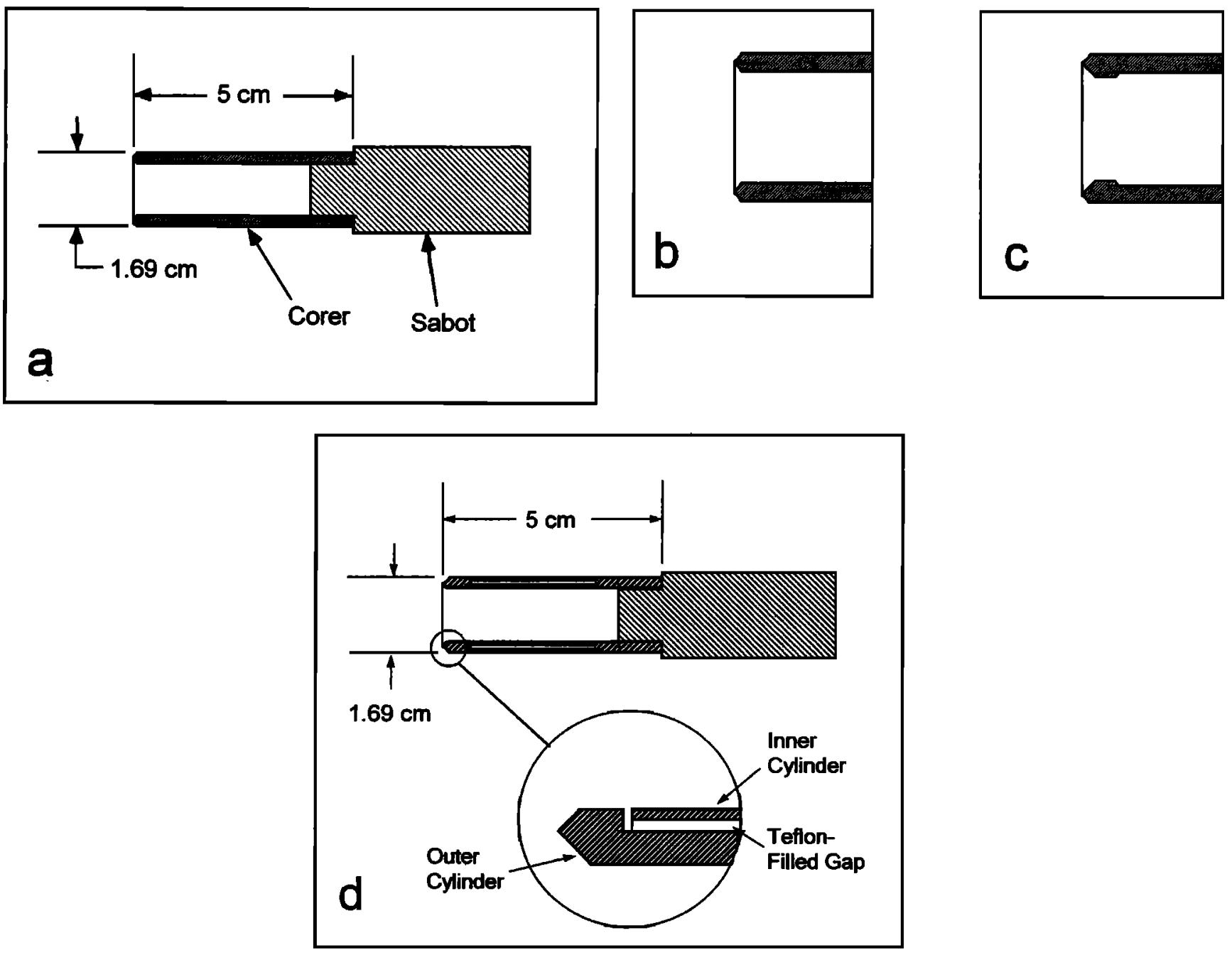

Figure 4. Gun-launched coring penetrator. (a) Overall penetrator design with sabot for $20-\mathrm{mm}$ gun. (b) Cross section of tip of penetrator with no lip. (c) Cross section of tip of penetrator having a lip on the inside. (d) Corer composed of concentric cylinders with a gap (typically filled by Teflon). 


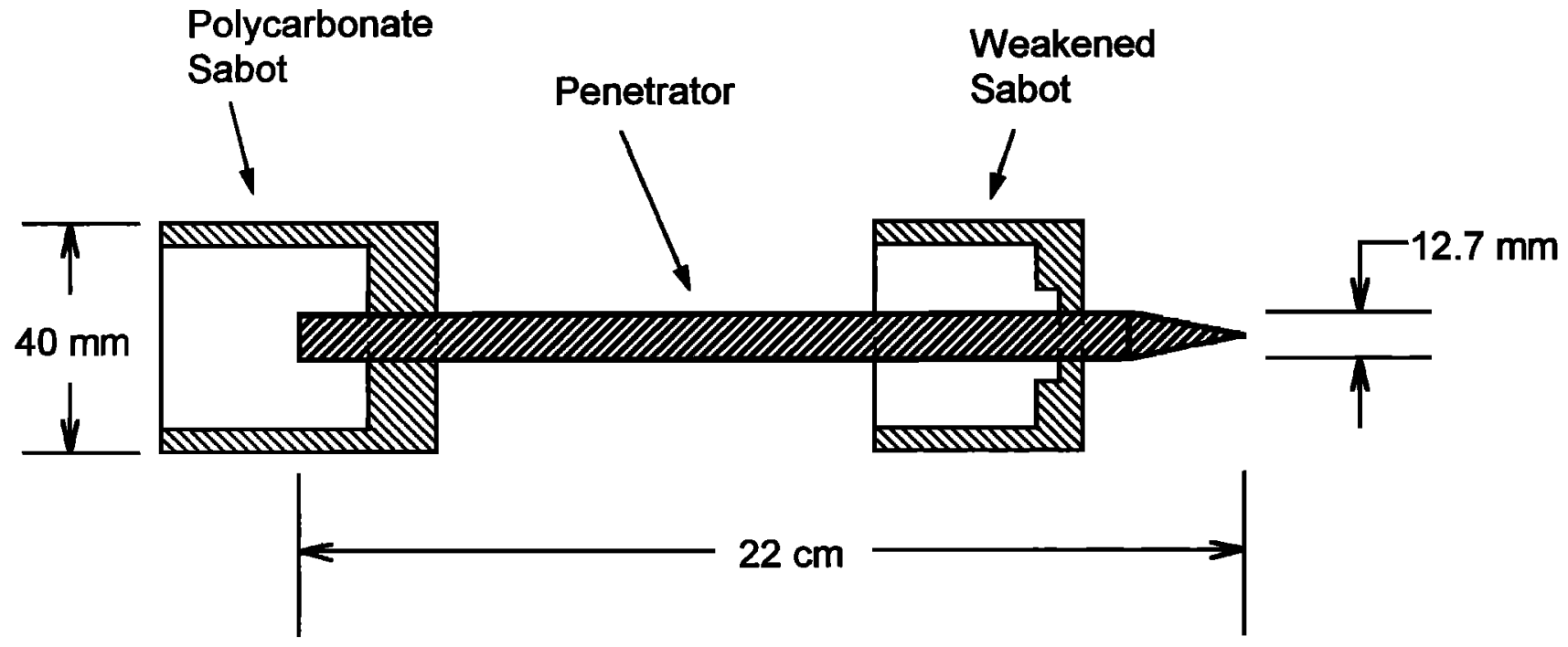

Figure 5. Gun-launched solid penetrator.

the initial shock condition, which we can approximate to first order as planar, which sets up the shock wave in the penetrator. It is the wave in the penetrator that is of importance here. The particle velocity imparted to the target by a plane shock wave is [Ahrens, 1987]

$$
\begin{gathered}
u_{p, T}=\frac{-b-\sqrt{b^{2}-4 a c}}{2 a} \\
a=s_{C} \rho_{C}-s_{T} \rho_{00, T} \\
b=-\left(C_{0, C} \rho_{C}+2 \rho_{C} s_{C} u_{0}+C_{0, T} \rho_{00, T}\right) \\
c=\rho_{C} u_{0}\left(C_{0, C}+s_{C} u_{0}\right)
\end{gathered}
$$

where subscripts $C$ and $T$ refer to the penetrator and target, respectively, $\rho_{C}$ is the density of the penetrator material, and $\rho_{00, T}$ is the initial bulk density of the target material. The subscript 00 is intended to indicate the possibility that the target is porous and may thus have a bulk density different from the intrinsic (i.e., nonporous) density of the material making up the target. Since we explicitly require the target to fail, we make the simplifying assumption that the target behaves as a fluid, so that $C_{0, T}=\left(K_{00 t} / \rho_{00 T}\right)^{1 / 2}$ and $s_{T}=\left[\left(\partial K_{00 t} / \partial P\right)_{S}+1\right] / 4$, where $K_{00 T}$ is the effective bulk modulus of the target material and $P$ is pressure in the (failed) target. In the case of the corer, the shock wave is a longitudinal elastic wave, so $C_{O C}=$ $\left(Y_{O C} / \rho_{C}\right)^{1 / 2}$ and $s_{C}=\left[\left(\partial Y_{O C} / \partial P\right)_{S}+1\right] / 4$, where $Y_{O C}$ is Young's modulus for the corer material. Since the velocity of the

\begin{tabular}{|c|c|c|c|c|c|c|}
\hline Material & $\rho_{00,}, \mathrm{Mg} / \mathrm{m}^{3}$ & $\sigma_{0}, \mathrm{MPa}$ & $\mu_{f}$ & $\sigma^{*}, \mathrm{MPa}^{\mathbf{a}}$ & $C_{0}, \mathbf{k m} / \mathrm{s}^{\mathrm{b}}$ & $s^{b}$ \\
\hline Perlite-plaster & 0.925 & 1.47 & 0.001 & 0.017 & - & - \\
\hline Perlite-cement (Series 4) & 1.045 & - & - & 0.86 & - & - \\
\hline Perlite-cement (Series 5) & 0.928 & - & - & 0.30 & - & - \\
\hline Perlite-cement (Series 6) & 0.945 & - & - & 0.59 & - & - \\
\hline Dover Chalk & 1.472 & 13 & 0.082 & $8.27^{\mathrm{cd}}$ & $0.667^{\circ}$ & $1.598^{\circ}$ \\
\hline Bedford limestone & 2.418 & 200 & - & 51 & $1.915^{\mathrm{f}}$ & $2.008^{f}$ \\
\hline Bishop Tuff & 1.420 & 43.7 & $0 . \overline{064}$ & $33^{\mathrm{Ed}}$ & $1.020^{b, d, 1}$ & $1.4^{b, d, 1}$ \\
\hline San Marcos Gabbro & $2.978^{\mathrm{h}}$ & - & - & $140^{\mathrm{cad}}$ & $2.526^{h}$ & $1.736^{\mathrm{h}}$ \\
\hline $\mathrm{C} 300$ & $8.091^{1}$ & - & - & - & $5.100^{h}$ & $0^{\mathrm{h}}$ \\
\hline SS304 & $7.870^{1}$ & - & - & - & $4.580^{\circ}$ & 1.49 \\
\hline AL2024 & $2.784^{b}$ & - & - & - & $5.330^{h}$ & $1.34^{\mathrm{h}}$ \\
\hline
\end{tabular}
penetrator material in contact with the target must equal $u_{p, r}$, the leading edge of the penetrator slows essentially instanta-

Table 1. Properties of Target and Penetrator Materials Used in This Study

- Unconfined uniaxial compressive strength.

b Shock wave parameter.

c Hatheway and Kiersch [1982].

d Property reported for similar rock from different locality.

- Tyburczy and Ahrens [1986].

${ }^{f}$ W. W. Anderson and T. J. Ahrens (manuscript in preparation, 1996).

B Olsson [1991].

h Marsh [1980].

i Interpolated from different densities.

j McQueen et al. [1970]. 
Table 2. Penetrator Experimental Results

\begin{tabular}{|c|c|c|c|c|c|}
\hline Experiment $t^{26}$ & Projectile Mass, g & $u_{0,} \mathrm{~m} / \mathrm{s}$ & $A_{x}, 10^{-4} \mathrm{~m}^{2}$ & Penetration Depth, cm & Comments \\
\hline PP-1-AL & 464.4 & 15.2 & 1.698 & 17.1 & Type 1. \\
\hline PP-2-AL & 464.4 & 15.2 & 1.698 & 15.2 & Type 1. \\
\hline PP-3-AL & 464.4 & 15.2 & 1.698 & 16.0 & Type 1. \\
\hline PP-4-SS & 1224 & 15.2 & 1.698 & 42.8 & Type 1. \\
\hline PP-5-SS & 1224 & 15.2 & 1.698 & 41.1 & Type 1. \\
\hline PP-6-SS & 1224 & 15.2 & 1.698 & 39.7 & Type 1. \\
\hline PP-7-AL & 464.4 & 15.2 & 1.698 & 15.7 & Type 1. \\
\hline PP-8-SS & 1224 & 15.2 & 1.698 & 39.5 & Type 1. \\
\hline PP-9-SS & 1224 & 15.2 & 1.698 & 40.6 & Type 1. \\
\hline PP-10-SS & 1224 & 10.2 & 1.698 & 21.6 & Type 1. \\
\hline PPF-1-SS & 1224 & 15.2 & 1.698 & 1.9 & Type 1. Not shown in Figure 6. \\
\hline PC4-1-AL & 464.4 & 15.0 & 1.698 & 2.5 & Type 1. Not shown in Figure 6. \\
\hline PC4-2-SS & 1224 & 15.2 & 1.698 & 5.7 & Type 1. Not shown in Figure 6. \\
\hline PC4-3-SS & 1224 & 15.2 & 1.698 & 5.1 & Type 1. Not shown in Figure 6. \\
\hline PC5-1-SS & 1224 & 15.5 & 1.698 & 11.4 & Type 1. Not shown in Figure 6. \\
\hline PC5-2-SS & 1224 & 15.5 & 1.698 & 10.3 & Type 1. Not shown in Figure 6. \\
\hline PC5-3-SS & 1224 & 15.5 & 1.698 & 11.0 & $\begin{array}{l}\text { Type 1. } 11^{\circ} \text { from normal. Not shown in } \\
\text { Figure } 6 \text {. }\end{array}$ \\
\hline PC6-1-SS & 1224 & 15.5 & 1.698 & 7.5 & Type 1. Not shown in Figure 6. \\
\hline PC6-2-SS & 1224 & 15.5 & 1.698 & 7.4 & Type 1. Not shown in Figure 6. \\
\hline $\mathrm{CH}-1-\mathrm{V}$ & 53.62 & 499 & 0.987 & 13.7 & $\begin{array}{l}\text { Type 2. Sabot stripped from penetrator by } \\
\text { target. Not shown in Figure } 6 \text {. }\end{array}$ \\
\hline$G-1-V$ & 53.63 & 528 & 0.987 & 1.6 & $\begin{array}{l}\text { Type 2. Coring cylinder shattered by im- } \\
\text { pact. Depth is depth of crater produced in } \\
\text { target by impact. Not shown in Figure } 6 \text {. }\end{array}$ \\
\hline CH-2-SS & 52.13 & 274 & 0.987 & 5.0 & $\begin{array}{l}\text { Type } 2 . \\
\text {. }\end{array}$ \\
\hline LS-1-V & 129.94 & 62.8 & 0.987 & 0.23 & Type 2. \\
\hline LS-2-V & 130.6 & 72.1 & 0.987 & 0.38 & Type 2. \\
\hline LS-3-V & 107.84 & 158.95 & 0.987 & 1.18 & Type 2. \\
\hline $\mathrm{CH}-4-\mathrm{V}$ & 109.09 & 38.47 & 0.987 & 1.14 & Type 2. \\
\hline $\mathrm{CH}-5-\mathrm{V}$ & 109.09 & 67.36 & 0.987 & 2.5 & Type 2. \\
\hline T-1-V & 107.27 & 73.7 & 0.987 & 2.07 & Type 2 . \\
\hline $\mathrm{T}-2-\mathrm{V}$ & 108.80 & 73.4 & 0.987 & 1.85 & $\begin{array}{l}\text { Type 2. } 20^{\circ} \text { from normal. Final orientation } \\
22^{\circ} \text { from normal. }\end{array}$ \\
\hline $\mathrm{T}-3-\mathrm{V}$ & 108.83 & 126.3 & 0.987 & & $\begin{array}{l}\text { Type } 2.40^{\circ} \text { from normal. Final orientation } \\
47^{\circ} \text { from normal. Sabot impacted target. } \\
\text { Not shown in Figure } 6 .\end{array}$ \\
\hline $\mathrm{T}-4-\mathrm{V}$ & 106.87 & 75.1 & 1.182 & 1.57 & Type 2. Lip on inside of corer leading edge. \\
\hline $\mathrm{T}-5-\mathrm{V}$ & 107.13 & 107.93 & 1.182 & 3.81 & Type 2. Lip on inside of corer leading edge. \\
\hline T-6-SS & 114.73 & 132.0 & 1.217 & 5.35 & $\begin{array}{l}\text { Type 2. Concentric sleeved corer. Outer } \\
\text { sleeve remained embedded in target. Not } \\
\text { shown in Figure } 6 \text {. }\end{array}$ \\
\hline PP-1-C & 222.64 & 104.43 & 1.267 & 34 & $\begin{array}{l}\text { Type 3. Penetrated through } 21 \mathrm{~cm} \text { of per- } \\
\text { lite-plaster mixture, } 6 \mathrm{~cm} \text { of cement, and } \\
\text { extended } 7 \mathrm{~cm} \text { from rear of target. Not } \\
\text { shown in figure } 6 \text {. }\end{array}$ \\
\hline $\mathrm{CH}-1-\mathrm{C}$ & 218.1 & 63.49 & 1.267 & 13.2 & Type 3. Not shown in Figure 6. \\
\hline LS-1-C & 219.35 & 55.97 & 1.267 & 0.64 & $\begin{array}{l}\text { Type 3. Tip of penetrator deformed on } \\
\text { impact. }\end{array}$ \\
\hline LS-4-V & 233.0 & 90.36 & 1.267 & 10.0 & $\begin{array}{l}\text { Type 3. Depth much greater than expected } \\
\text { due to propagation of crack ahead of pene- } \\
\text { trator tip. Not shown in Figure } 6 \text {. }\end{array}$ \\
\hline
\end{tabular}

'Prefix denotes target material: PP, perlite-plaster mixture; PPF, frozen perlite plaster mixture; PC4, PC5, PC6, perlite-cement mixtures, series 4, 5, and 6; CH, Dover Chalk embedded in cement; G, San Marcos Gabbro; LS, Oolitic Limestone; T, Bishop Tuff.

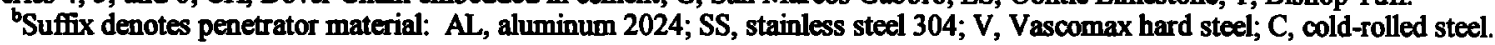




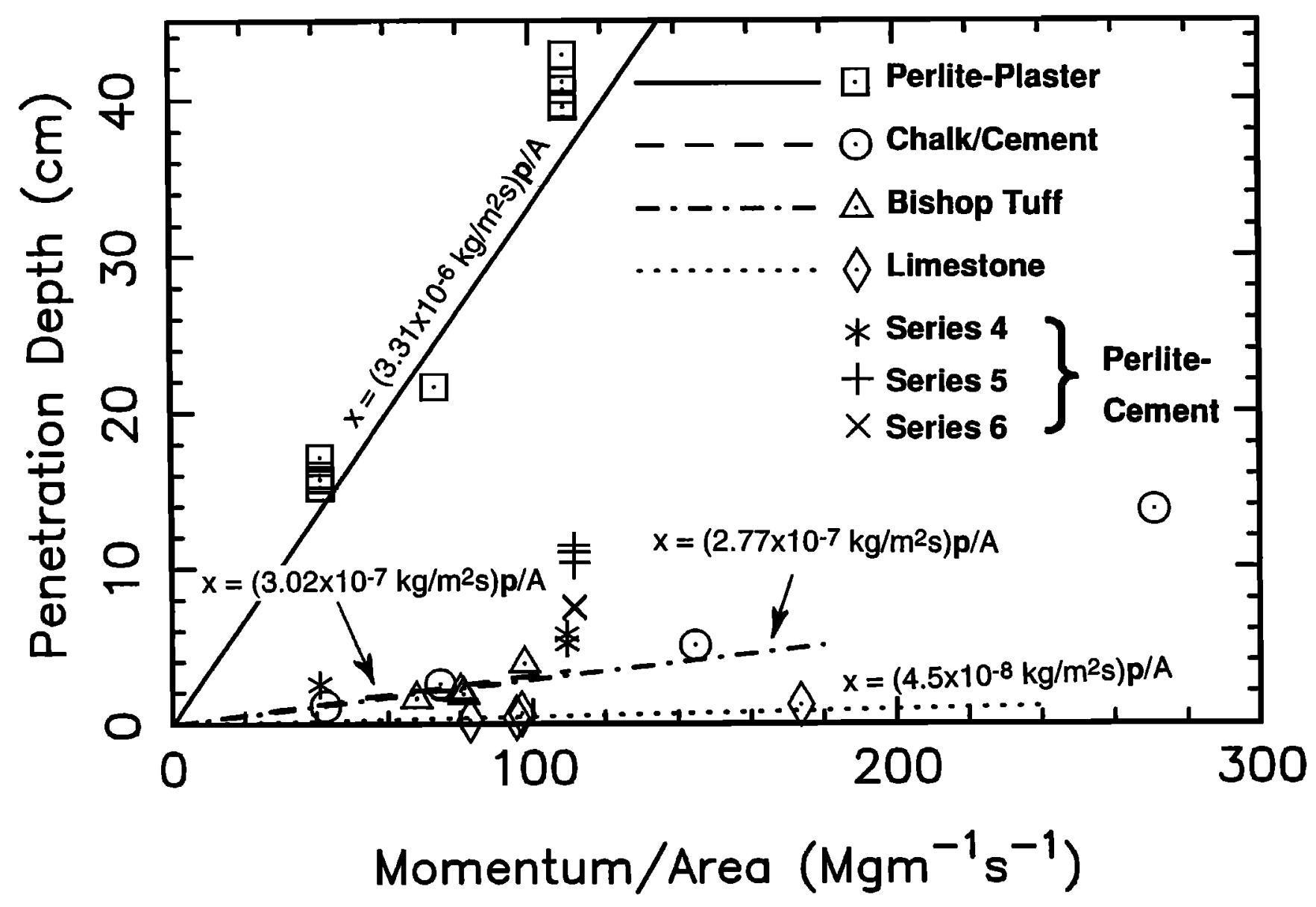

Figure 6. Summary of the impact penetration experiments. The data are presented as depth of penetration versus the ratio of momentum to frontal surface area of the penetrator.

neously to $u_{p, T}$. The elastic compressional wave travels the length of the penetrator, reflecting from the rear surface as a tensile elastic wave imparting a further velocity decrease of similar magnitude. Our model simplifies these initial complications by assuming that the initial slowing of the penetrator occurs at the moment of first contact with the target. We then consider the initial velocity of penetration as being

$$
u_{i}=2 u_{p, T}-u_{0}
$$

For impacts of SS304 penetrators into chalk, $u_{i}$ is typically $\sim 5$ $10 \%$ smaller than $u_{0}$.

The motion of the penetrator after contact with the target is described by Newton's second law:

$$
\begin{gathered}
\frac{d \mathrm{p}}{d t}=-\mathrm{F} \\
|\mathrm{p}|=m u=m \frac{d x}{d t}
\end{gathered}
$$

where $x$ is depth of the leading edge of the penetrator, $m$ is the mass of the penetrator, and $F$ is the decelerating force. We must write the equation of motion in terms of the momentum p because of the possibility that a closed-ended coring penetrator could be completely filled with target material, in which case the mass of the contained core is accelerated as it is compacted and effectively becomes part of the penetrator mass.
Thus $m$ can vary with time. The deceleration magnitude $-\dot{u}=$ $-d^{2} x / d t^{2}$ is given by

$$
-\dot{u}=\frac{F+u d m / d t}{m}
$$

The decelerating force is composed of two orthogonal components, $F_{1}$ and $F_{t}$, acting normal and tangent, respectively, to the surface of the penetrator. The components of these forces acting to decelerate the penetrator are

$$
\begin{gathered}
F_{n}=\iint_{S_{w}}\left(C_{d} P_{d}+\sigma_{d}\right) \cos \theta d s \\
F_{t}=\iint_{S_{w}}\left(C_{d} P_{d}+\sigma_{d}\right) \mu_{f} \sin \theta d s
\end{gathered}
$$

where $s_{w}$ is the surface "wetted" by (i.e., in contact with) the target material, $\theta$ is the angle between the normal to the surface and the direction of motion (Figure 7), $\mu_{j}$ is the coefficient of dynamic friction of the failed target material against the penetrator surface, and $\sigma_{d}$ is the deviatoric stress component normal to the surface. $C_{d}$ is a stress concentration factor, somewhat like a drag coefficient, but resulting from the dynamic pressure being applied over the surface of the deflected flow and so concentrating a larger force at the surface of the 

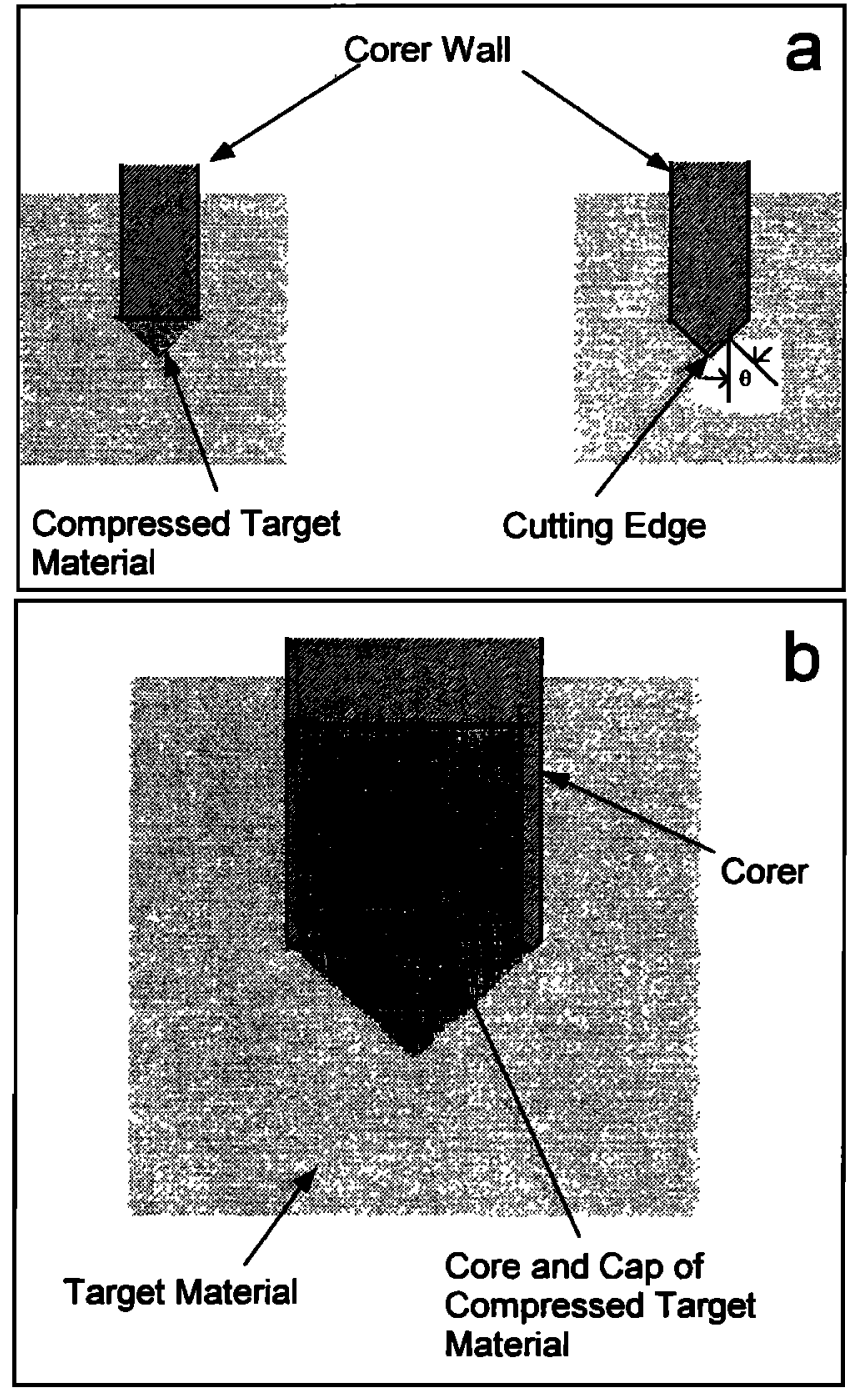

Figure 7. Schematic depiction of the behavior of the target material at the front of the penetrator and the definition of angle $\theta$ used in this study. (a) For penetrator with a blunt leading edge, an annulus of compressed target material forms a cutting edge with a $45^{\circ}$ failure surface, while no buildup of target material occurs if the penetrator has a cutting edge. (b) Once the penetrator interior is filled with target material, the penetrator builds up a conical cap of compressed target material.

penetrator. A typical value is $C_{d}=2$, which we use here. Continuing our assumption of fluid-like behavior for the failed target material, the dynamic pressure $P_{d}$ is given by

$$
P_{d}=\frac{1}{2} \rho_{00} u^{2} \cos ^{2} \theta
$$

where $u$ is the velocity of the penetrator and $p_{00}$ is the bulk density of the target material. There is no shock pressure term because the release wave reflected from the rear of the penetrator propagates well ahead of the penetrator. Since we assume that the target material fails mechanically during the penetration process, the quantity $\sigma_{d}$ is the stress supported by the target at incipient failure. Because in practice, material is forced to the sides as well as forward from the penetrator, the value of $\sigma_{d}$ should not be sensitive to $\theta$. The strength may also be strain-rate dependent. We will return to the issue of the target material strength in the next section.

The deceleration rate in (10) is found by substituting for $F$ the expressions in (11) and (12):

$$
\dot{u}=-\frac{1}{m}\left[\int_{s_{w}}\left(P_{d}+\sigma_{d}\right)\left(\cos \theta+\mu_{f} \sin \theta\right) d s\right]
$$

The penetration depth $x$ at time $t$ is obtained by integrating this expression twice with respect to time, using $u=u_{i}$ and $t=$ 0 as the initial conditions:

$$
\begin{aligned}
x(t) & =\int_{0}^{t}\left\{u_{i}-\int_{0}^{t^{\prime}} \frac{1}{m}\left[u \frac{d m}{d t}+\iint_{s_{w}}\left(P_{d}+\sigma_{d}\right)(\cos \theta\right.\right. \\
& \left.\left.\left.+\mu_{f} \sin \theta\right) d s\right] d \tau\right\} d t^{\prime}
\end{aligned}
$$

where $\tau$ is the argument of the inner integral over time.

Determination of the amount of penetrator surface area in contact with the target material (i.e., $s_{w}$ ) requires some care. Target material in the path of the penetrator will be forced to the side (either outward away from the penetrator or in toward the axis of the penetrator). The speed of this deflected material is reduced from the free-field flow speed by the factor $\rho_{0} / \rho_{L}$, where $\rho_{L}$ is the bulk density of the compressed target material. We will assume that the deflected flow is parallel to the penetrator surface at the deflection point. Under this condition, the flow velocity perpendicular to the axis of the penetrator is $\left(\rho_{0 o} / \rho_{L}\right) u \cos \theta$. In order for a particle in the deflected flow to recontact the penetrator to the rear of the deflection point, one of two conditions must be met. If the value of $\theta$ decreases rearward from the deflection point, the flow will recontact the surface and be further deflected. If the value of $\theta$ is larger than or equal to that at upstream deflection points, then the rebound velocity $u_{f s}$ due to stored strain energy in the compressed target material must exceed the outward flow velocity. The onset of rebound is instantaneous, and the only question is whether $u_{f s}$ is sufficient to reverse the outward flow. The rebound is normal to the wall of the conical cavity formed by the outward flow, which is parallel to the original deflecting surface. As a result, the inward component of the rebound flow is $u_{f s} \sin \theta$. The outward flow is reversed if this component is greater than the outward flow velocity component. Hence a surface is wetted when the flow deflected by a forward portion of the penetrator satisfies the condition

$$
\frac{\rho_{L} u_{f s}}{\rho_{00} u} \tan \theta>1
$$

We assume that surfaces with $\theta<0$ are never contacted by the flow.

If the rebound velocity $u_{f s}$ results from conversion of internal strain energy of compression in the target to kinetic energy, then

$$
u_{f s} \cong\left[\left(P_{d}+\sigma_{d}\right)\left(\rho_{00}^{-1}-\rho_{L}^{-1}\right)\right]^{1 / 2}
$$


For the value of $\rho_{L}$, we assume the density of the target material at which the particles become close-packed, or "locked". If the initial density $\rho_{00}<0.74 \rho_{0}$, i.e., the density of closepacked spheres, then we assume that $\rho_{L}=0.74 p_{0}$. Otherwise, $\rho_{L}=\rho_{00}$. This suggests a qualitative difference between impacts into dense, low-porosity targets and those with high porosities. If the target material is dense and incompressible, it fails by brittle fracture and, at least near the target surface, spalled material is not able to exert a restoring force and permanently loses contact with the corer.

The assumption that compaction does not proceed past $0.74 \rho_{0}$ has an interesting consequence for the final condition of a core sample. Let us assume that the front of a corer has a beveled edge, so that material on one side of the bevel is directed toward the centerline of the corer, while material on the other side is directed outward. We assume that all of the material directed inward will be "ingested" by the penetrator and become part of the core sample. In the process of being ingested, that material must be compressed enough to pass through the most restricted part of the entrance to the sample cavity. If the compression (taken to be the ratio of the area circumscribed by the beveled cutting edge to the crosssectional area of the most restricted part of the opening) is such that the density of the target material would exceed $0.74 \rho_{0}$, then the material must be extruded into the cavity. For a brittle material, this requires shear failure, resulting in a fragmented sample. If, however, the compression would not cause the density to exceed $0.74 p_{0}$, then the sample will probably be collected as a nearly coherent cylinder of material held tightly in place by the friction forces due to $\sigma_{d}$.

The time-varying quantities in (15) (i.e., $m, u, P_{d}$, and $s_{w}$ ) depend on time only via their dependence on $x$ or $u$, so that we can differentiate them with respect to $t$ to arbitrarily large order. We could thus, in principle, take arbitrarily large time steps while calculating the progress of the penetration process. However, complications arising from the rapid increase in mass as a corer is filled and from variations in the crosssectional area of the penetrator at different points along its length, as well as the effect of velocity on wetting of some surfaces, make this impractical. Because the equations for $F_{n}$ and $F_{t}$ become cumbersome as higher order time derivatives of $u$ and $x$ are taken, we usually take the derivatives only to second order in $t$ for numerical solution of (15).

\section{Effective Bearing Strength $\sigma_{d}$}

The quantity $\sigma_{d}$ is taken to be the maximum normal stress on the surface of a half-space that can be supported without the material failing in compression. The penetrator velocities being considered in this study are low enough that the dynamic pressure $P_{d}$ is usually less than $\sigma_{d}$ (1-10 MPa for $P_{d}$ versus 10-100 MPa for $\sigma_{d}$ ). As a result, the dominant decelerating force is usually supplied by $\sigma_{d}$.

The behavior of $\sigma_{d}$ can be described using the damage mechanics model of Ashby and Sammis [1990] by including time- and rate-dependent effects. Their model treats compressional failure as the growth of cracks, resulting from strain caused by applied stress. While Ashby and Sammis [1990] limited their discussion to the quasi-static case, the model can be extended to the dynamic situation. A crack in some medium grows whenever the stress at the crack tip is greater than a critical stress $K_{I C}$, but the propagation speed of a crack tip is limited by the elastic wave speed of the material making up the medium. If the deformation rate is low, the crack will grow only fast enough to maintain the tip stress at $K_{I C}$, so that the macroscopic result is a strength that is independent of strain rate. If the deformation rate is fast, then the crack tip cannot propagate fast enough to relieve the stress, which grows linearly with time until the stress is relieved by the crack intersecting another crack. The strength in that case is a result of the complicated balance between stress growth on growing cracks and stress relief on intersecting cracks, but most importantly, is rate-dependent. Qualitatively, $\sigma_{d}$ is constant below some critical strain rate $\dot{\varepsilon}_{c}$, but depends on $\dot{\varepsilon}$ above $\dot{\varepsilon}_{c}$. This phenomenon is in fact observed for rocks [e.g., Olsson, 1991; Kumar, 1968; Green and Perkins, 1970; Perkins et al., 1970].

From a practical standpoint, first principles calculation of $\sigma$ $d$ is extremely difficult because of the complicated geometries of the preexisting flaw populations in real materials. For the present study, we assume that $\sigma_{d}$ is proportional to some power of $\dot{\varepsilon}$ when $\dot{\varepsilon}>\dot{\varepsilon}_{c}$. Since the style of strain is flexure of individual grains, the relevant length scale for defining the strain rate is the average grain size. In such a case, the strain rate is independent of penetrator dimensions, so that the critical penetration speed $u_{c}$, at which the critical strain rate is achieved, is a property of the target and is completely independent of the penetrator. Hence we use

$$
\begin{array}{cc}
\sigma_{d}=\sigma_{0} & u<u_{c} \\
\sigma_{d}=\sigma_{0}\left(\frac{u}{u_{c}}\right)^{n} & u \geq u_{c}
\end{array}
$$

Based on the work of Grady and Kipp [1987], $n \approx 1 / 3$ for most materials.

\section{Effects of Penetrator Shape and Complete Filling of Corers}

There are two special situations that we must consider (Figure 7). The first is the behavior of the flow when the minimum value of $\theta$ is less than $\pi / 4$. Any surface where $\theta<$ $\pi / 4$ will develop a cap of compressed target material ahead of it. The cap is bounded by shear failure surfaces, oriented $\sim 45^{\circ}$ from the penetrator propagation direction, resulting from nonhydrostatic stresses in the cap. Hollow corers with blunt leading edges build up an annular cap of compacted target material, while solid penetrators build up a conical cap. The beveled failure surfaces cause the cap to act as a cutting edge or point. The flow impinges on this cap and is deflected, as discussed earlier, as if the cap were an integral part of the penetrator itself. The mass of this cap, which forms almost immediately upon impact, effectively becomes part of the penetrator mass.

The second situation is the case of a hollow penetrator being completely filled. When target material extruding into the interior of the penetrator completely fills the internal cavity, a compressional wave propagates forward from the rear surface of the cavity, compacting the target material to its locked density. The mass of material so compacted, which increases with time until the wave reaches the front of the penetrator, is accelerated to the speed of the penetrator. The speed of the wave is controlled by the speed of the penetrator and the requirement for conservation of mass. In the special case of the 
material inside the penetrator already being at or above its locked density, the speed of the wave is assumed to be the compressional elastic wave speed of the material. In addition to the penetrator gaining mass, as the material inside it is compacted, the front of the penetrator effectively changes shape, building up a conical cap as described above, once the contained material is fully compacted.

\section{Lateral Forces}

The present model explicitly assumes that the penetrator is at least bilaterally symmetrical across two mirror planes parallel to the direction of travel and that the impact is normal to the target surface, so that there are no net torques applied by lateral forces acting on the front of the penetrator. Such restrictive conditions are seldom met in practice. We performed three coring impact experiments (PC5-3-SS, T-2-V, and T-3$\mathrm{V})$ with nonnormal geometry to investigate the consequences of impact angle on the penetration process. The largest deviation from normal was $40^{\circ}$ for impact into tuff. The total deflection of the penetrator was $7^{\circ}$, so that the final orientation of the coring tube was $47^{\circ}$ from normal, while the mean penetration depth in the direction of travel was indistinguishable from that expected for a normal impact. The problem of solid penetrators impacting unconsolidated targets was studied by Suzuki et al. [1994], who found that the greatest deflection occurs while part of the penetrator remains outside the target. Their work suggests a larger deflection for solid penetrators, but also suggests that penetration (as opposed to ricochet) occurs even in impacts $50^{\circ}$ from normal for penetrators of a few kilograms mass and diameters of $0.15 \mathrm{~m}$ impacting lunar soil at $300 \mathrm{~m} / \mathrm{s}$. The combination of these studies suggests that nonnormal impact has a relatively minor effect on the outcome.

A more serious problem is impact in which the penetrator axis is not parallel to the velocity vector. Unfortunately, this situation is more difficult to arrange under controlled experimental conditions. Numerical models for solid penetrators [Suzuki et al., 1994] show that the effects of a nonzero angle of attack can result in significant redirection of the velocity vector. We expect that the same should be true of hollow penetrators, since the shape of the front (i.e., open or closed) is relatively unimportant if the side of the penetrator dominates the surface area seen by the target viewing back along the velocity vector.

\section{Comparison of Data With Theory}

We use a one-dimensional finite difference code based on our model to calculate the penetration behavior of a penetrator into a target. To calculate the progress of penetration as a function of time, we calculate the values of $F_{t}, F_{n}$, and $d m / d t$ to obtain the deceleration du/dt. This then allows the calculation of $d F_{t} / d t, d F_{n} / d t$, and $d^{2} m / d t^{2}$, consequently giving $d^{2} u / d t^{2}$. In a few special cases, where the equations are particularly simple, the derivatives are taken to third order. It should be noted that the mass varies only when a corer is completely filled but the core is not yet compressed to $\rho_{L}$. We use the derivatives of $F_{t}, F_{n}$, and $m$ to numerically integrate the expression in (15) using a variable time step size to improve efficiency while not sacrificing accuracy. The code recognizes discontinuities in target properties in layered targets. It also takes filling of the corer into account and automatically rescales the step size to account for such rapidly varying parameter values.

Of the various parameters in our model, the only ones that are not well known a priori are $u_{c}$ and $n$ in (18). The value of $\sigma_{0}$ for each material is available from the quasi-static penetration experiments (being the intercept of the force/area versus depth curves). We also choose to use the value of $\mu$ fobtained from the static penetration experiments (Figure 3 ), even though the dynamic value will differ somewhat from the measured (static) value. We also assumed that all penetrator materials have the same value of $\mu$ with a given target material. Table 3 gives the values of the various parameters used in this study. We assumed that the inner surfaces of the "lipped" corers (experiments T-4-V and T-6-V), were not wetted.

Figure 8 shows the comparison of the theory with the data for several different target materials obtained by varying $u_{c}$ as the only free parameter (values of parameters are listed in Table 3 ). Both solid and coring penetrators are included in the figure, showing that our model successfully describes penetration by both types of penetrators. We assume $n=1 / 3$ for all target materials except for extremely porous materials, such as the perlite-plaster mixture, $n \approx 0$. The $n=0$ assumption follows from the very small amount of crack growth required to connect voids. Thus the primary source of strength for these materials is sliding friction of collapsed void faces, which is rate-independent. Because of the lack of sufficient material property measurements and limited penetration data, the re-

Table 3. Model Parameters for Target Materials

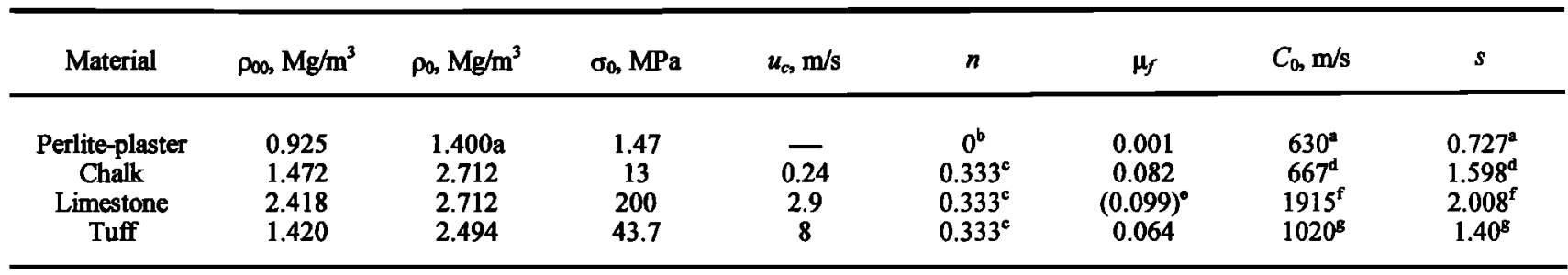

"Estimated from composition.

${ }^{b}$ Assumed.

'Grady and Kipp [1987].

'Tyburczy and Ahrens [1986].

Estimate from value for chalk and relative densities of compacted states.

fW. W. Anderson and T. J. Ahrens (manuscript in preparation, 1996).

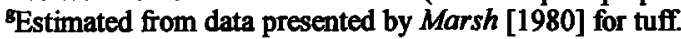




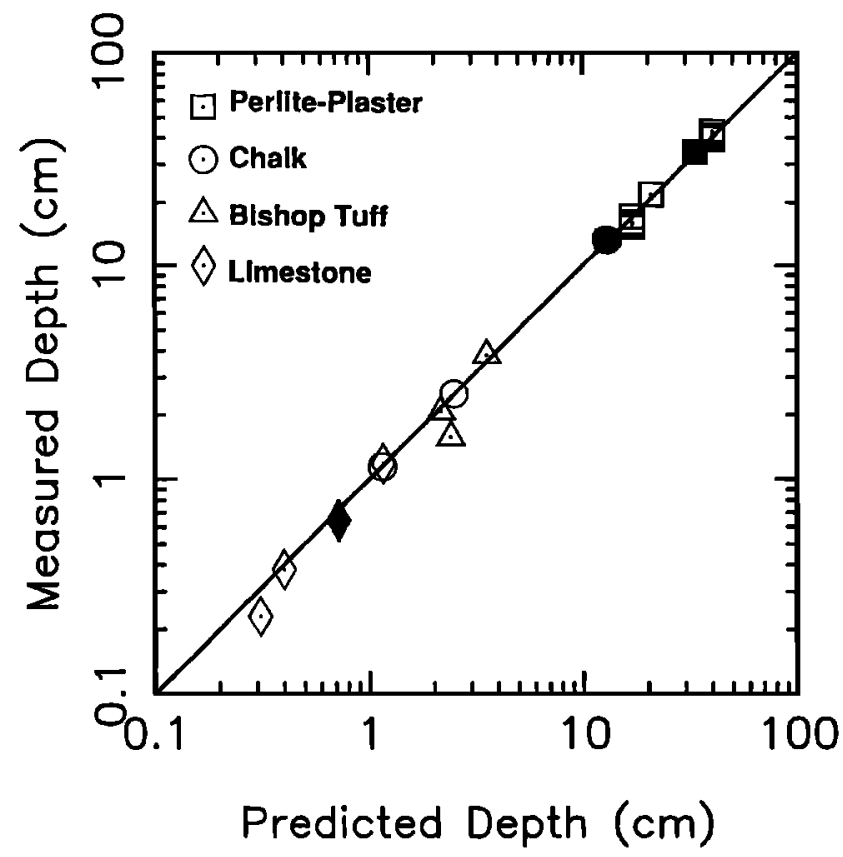

Figure 8. Comparison of penetration depths predicted by the model with those observed in the experiments. Open symbols are for coring penetrators and solid symbols are for solid penetrators.
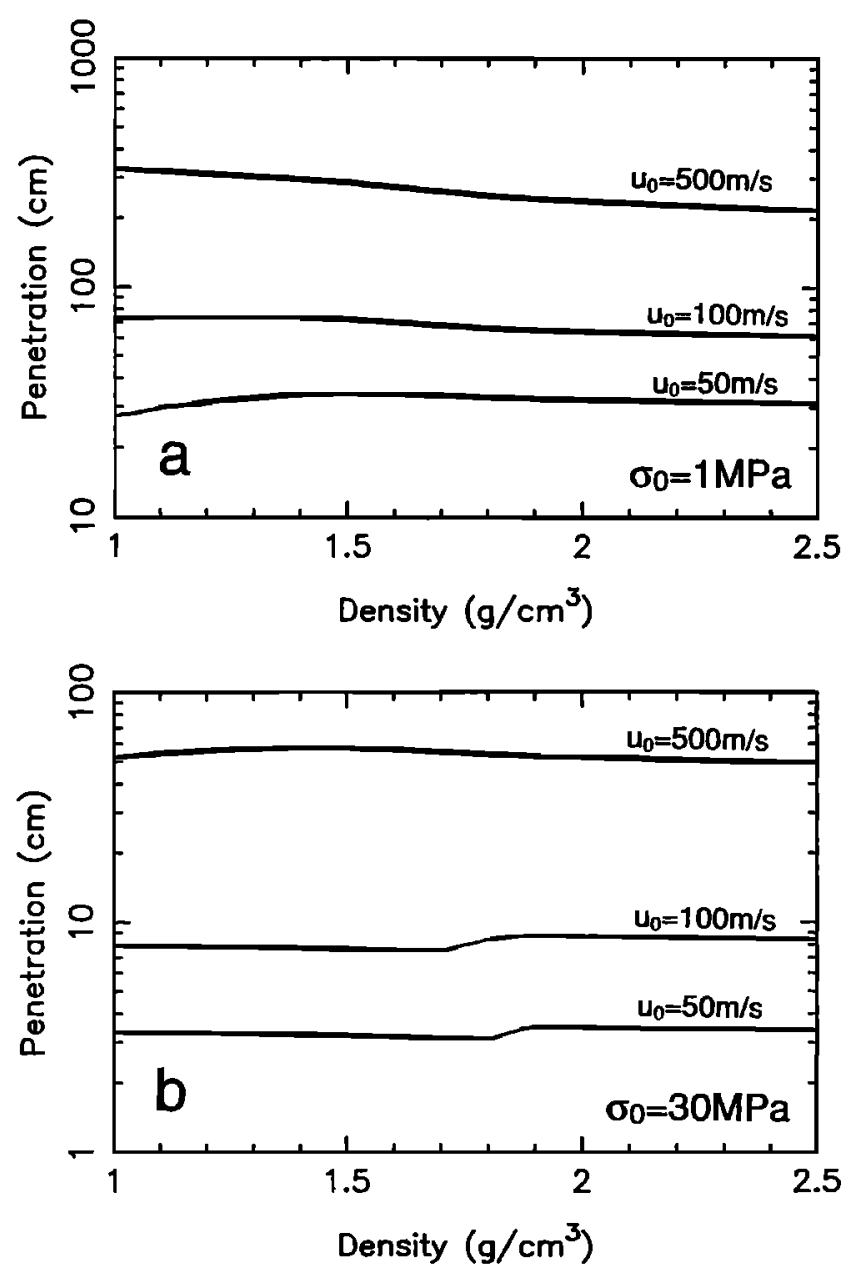

Figure 9. Effect of varying target bulk density on the depth of penetration.

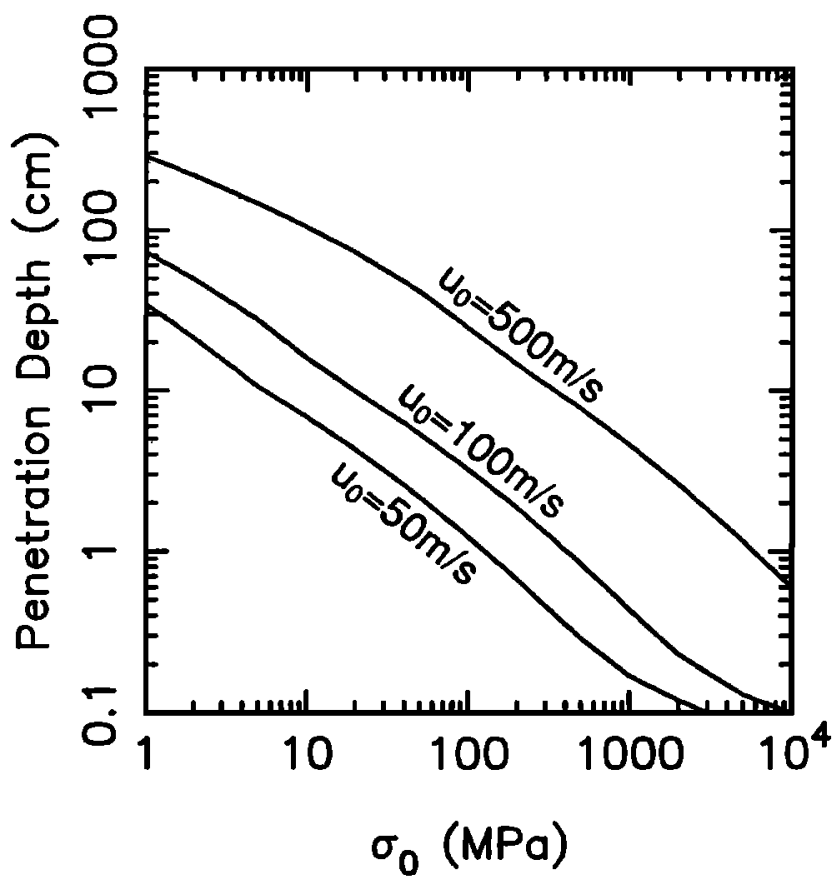

Figure 10. Effect of varying static effect strength of the target material.

sults for the perlite-cement mixtures and San Marcos Gabbro are not shown in Figure 8. For well-characterized materials, the agreement between the data and the theory is excellent.

One qualitative result not shown by the plots is the coherence of the sample inside a coring penetrator. When samples are compressed to densities greater than $0.74 \rho_{0}$, fragmentation occurs as discussed earlier. If the final state of the sample is less than $0.74 p_{0}$, the final condition of the sample was a compact, coherent core, usually so tightly held by friction forces inside the corer that machining is required to extract the sample.

\section{Trends in Penetration Depth Dependence}

The present model allows prediction of the effects of varying material parameters and impact velocities on penetration. Such predictions are useful for relating penetrator designs to performance. We examine the effects of varying $\rho_{00}, \sigma_{0}$, and $\mu_{f}$. We define a nominal target having $\rho_{00}=1.6 \mathrm{Mg} / \mathrm{m} 3, \rho_{0}=$ $2.5 \mathrm{Mg} / \mathrm{m} 3, \sigma_{0}=30 \mathrm{MPa}, u_{c}=1 \mathrm{~m} / \mathrm{s}, n=1 / 3, \mu_{f}=0.10, C_{0}=$ $1.02 \mathrm{~km} / \mathrm{s}$, and $s=1.4$. The effect of varying each parameter is studied independently, except that variations of $p_{00}$ are examined at $\sigma_{0}=30 \mathrm{MPa}$ and $\sigma_{0}=1 \mathrm{MPa}$. A 20-mm-diameter coring penetrator with 2-mm-thick walls and a mass of $0.5 \mathrm{~kg}$, made of Vascomax C-300 steel is assumed. The length was assumed infinite to assure that the results would not be complicated by the penetration depth exceeding the penetrator length. The penetrator was assumed to have a leading edge with inner and outer $45^{\circ}$ bevels forming a cutting edge.

Figures 9-11 show the effects of varying $\rho_{00}, \sigma_{0}$, and $\mu_{f}$. In these figures, the relative importance of different parameters in determining the total deceleration force can be determined by the effect that varying the parameters has on the total penetration depth. Figure 9 shows the effect of varying the target density at two different target strengths. Since the part of the decelerating force that explicitly depends on density is 


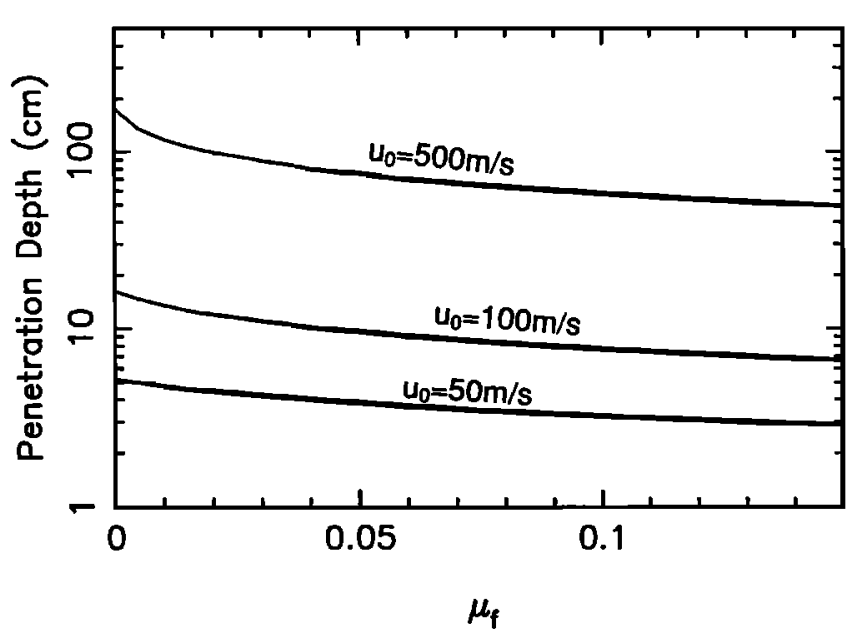

Figure 11. Effect of varying friction coefficient of the target material with the penetrator.

the dynamic pressure, the very weak dependence of penetration depth on density shows that the dynamic pressure is not the primary source of the deceleration force for materials exhibiting strength. The increase in penetration depth with increasing density over some ranges of conditions, resulting in maxima in the curves, is a consequence of two separate but related effects. The discontinuities in two curves in Figure 9b are the consequence of the initial target density increasing to the point that the target material is initially at or above its locked density. This results in macroscopic fracturing and mitigates friction as an important factor in the deceleration process, since there is no rebound. The effect is noticeable only at the higher strength because $\sigma_{d}$ is the only normal stress acting against the side of the penetrator (where $\boldsymbol{P}_{d}$ vanishes). The slow rise at lower values of $p_{00}$ is the result of the rebound velocity given in (17) being insufficient at early times in the penetration to cause contact of the target material with the penetrator. We can see in Figure 10 that the penetration depth at any given velocity is almost inversely proportional to $\sigma_{0}$, confirming the dominance of material strength in controlling the penetration process for competent targets. The curvature in the penetration curves is the result of variation in the amount of area upon which friction is operating, caused by differences in penetrator depth. However, Figure 11 shows that varying $\mu_{f}$ can also have important consequences, especially at high velocities. At $u_{0}=500 \mathrm{~m} / \mathrm{s}$, variation of $\mu_{f}$ from 0 to 0.15 results in a factor of $\sim 3$ change in penetration depth. At lower velocities, friction is less important because the smaller penetration causes relatively little of the penetrator surface to be in contact with the target.

\section{Summary}

The present model takes into account the key physical phenomena operating during impact of both hollow and solid penetrators. It accurately predicts the dependence of penetration depth on the various parameters of the target-penetrator system, as well as the qualitative condition of target material ingested by a corer. If passage through the mouth of a corer requires that the brittle target material be compressed to $<26 \%$ porosity, we predict that the sample collected by the corer will be fragmented. If the porosity remains above $26 \%$, then all but cohesionless materials, such as dry sand, will be collected as a compressed slug of material.

The most important parameter affecting the penetration depth for targets with finite strength is the strength of the target material. The experiments showed that the penetration depth is proportional to the ratio of momentum to frontal area of the penetrator. The inverse of the proportionality constant has units of shock impedance and shows that strong materials are more resistant to penetration. The effective target strength, which is typically considerably higher than the uniaxial compressive strength of the target material, can be described by a dynamic version of the Ashby and Sammis [1990] damage mechanics model. The model successfully predicts the observed behavior of rocks, in which strength is relatively constant below some critical strain rate and dependent on the strain rate above that critical strain rate. We find that strength is the most important factor controlling penetration, although friction can be significant at high impact velocities. The calculations show that bulk density of the target material has only a second order effect. The present results suggest that the depth of penetration is a good measure of the strength of a target, but will not provide explicit information on target density.

Acknowledgments. We thank M. Forrestal and an anonymous reviewer for helpful discussion and comments. Research was supported by NASA grant NAGW-2439 and NASA/Jet Propulsion Laboratory. Division of Geological and Planetary Sciences contribution 5578.

\section{References}

Ahrens, T. J., Shock wave techniques for geophysics and planetary physics, in Methods of Experimental Physics 24, edited by C. G. Sammis and T. L. Henyey, pp 185-235, Academic, San Diego, Calif., 1987.

Ahrens, T. J., J. H. Lower, and P. L. Laqus, Equation of state of forsterite, J. Geophys. Res., 76, 518-528, 1971.

Allen, W. A., E. B. Mayfield, and H. L. Morrison, Dynamics of a projectile penetrating sand, J. Appl. Phys., 28, 370-376, 1957.

Ashby, M. F., and C. G. Sammis, The damage mechanics of brittle solids in compression, Pure Appl. Geophys., 133, 489-521, 1990.

Forrestal, M. J., and V. K. Luk, Penetration into soil targets, Int. J. Impact Eng., 12, 427-444, 1992.

Forrestal, M. J., B. S. Altman, J. D. Cargile, and S. J. Hanchak, An empirical equation for penetration depth of ogive-nose projectiles into concrete targets, Int. J. Impact Eng., 15, 395-405, 1994.

Grady, D. E., and M. E. Kipp, Dynamic rock fragmentation, in Fracture Mechanics of Rock, edited by B. K. Atkinson, Academic, New York, NY, pp. 429-475, 1987.

Green, S. J., and R. D., Perkins, Uniaxial compression test at varying strain rates on three geologic materials. Proc. U.S. Rock Mech. Symp., Soc. Min. Eng. AIME, 10th, 33-54, 1970.

Hatheway, A. W., and G. A. Kiersch, Engineering properties of rocks, in CRC Handbook of Physical Properties of Rocks, vol. 2, edited by R. S. Carmichael, pp. 289-331, CRC Press, Boca Raton, Fla., 1982.

Kumar, A., The effect of stress rate and temperature on the strength of basalt and granite, Geophysics, 33, 501-510, 1968.

Marsh, S. P., LASL Shock Hugoniot Data, 651 pp., Univ. of Calif. Press, Los Angeles, 1980.

McQueen, R. G., S. P. Marsh, J. W. Taylor, J. N. Fritz, and W. J. Carter, The equation of state of solids from shock wave studies, in High Velocity Impact Phenomena, edited by R. Kinslow, pp. 293417, Academic, San Diego, Calif., 1970.

Murff, J. D., and H. M. Coyle, Prediction method for projectile penetration, J. Soil Mech. Found. Div. Am. Soc. Civ. Eng., 99, 10331037, 1973. 
Olsson, W. A, The compressive strength of tuff as a function of strain rate from 10-6 to $103 / \mathrm{sec}$, Int. J. Rock Mech. Min Sci. Geomech. Abstr., 28, 115-118, 1991.

Perkins, R. D., S. J. Green, and M. Friedman, Uniaxial stress behavior of porphyritic tonalite at strain rates to $10^{3} /$ second, Int. J. Rock Mech. Min. Sci., 7, 527-535, 1970.

Suzuki, K., T. Abe, A Fujimura, M. Hayakawa, S. Tanaka, and H. Mizutani, Analytical model of penetration dynamics into lunar soil with lateral loading, paper presented at the 4th Workshop on Astrodynamics and Flight Mechanics, Institute for Space and Astronautical Sciences, Sagamihara, Japan, Aug. 29-30, 1994.

Tyburczy, J. A., and T. J. Ahrens, Dynamic compression and volatile release of carbonates, J. Geophys. Res., 91, 4730-4744, 1986.

Wang, W. L., Low velocity projectile penetration, J. Soil Mech. Found.Div. Am. Soc. Civ. Eng., 97, 1635-1655, 1971.
T. J. Ahrens, Seismological Laboratory, 252-21, California Institute of Technology, Pasadena, CA 91125. (e-mail: tja@seismo.gps.caltech.edu)

W. W. Anderson, Department of Geology and Physics, Georgia Southwestem State University, 800 Wheatley Street, Americus, GA 31709-4693. (e-mail: bill@gswl500.gsw.peachnet.edu)

A. Gibson and R. Scott, Division of Engineering and Applied Science, California Institute of Technology, Pasadena, CA 91125.

K. Suzuki, Department of Aeronautics and Astronautics, Faculty of Engineering, University of Tokyo, Hongo 7-3-1, Bunkyo, Tokyo 113, Japan.

(Recieved July 21, 1995; revised March 17, 1996; accepted May 2, 1996.) 